\title{
APPLICATION OF PHB-LIPOSOME PARTICLES AND NANOFIBERS IN COSMETICS
}

\author{
Renata PAVELKOVÁ, Monika PLACHÁ, Matej TARAGEL', Agáta BENDOVÁ, \\ Petra MATOUŠKOVÁ, Ivana MÁROVÁ \\ Institute of Food Science and Biotechnology, Faculty of Chemistry, Brno University of Technology, Brno, \\ Czech Republic, EU, xcpavelkovar@fch.vut.cz
}

https://doi.org/10.37904/nanocon.2019.8709

\begin{abstract}
Liposomes are versatile systems for drug delivery. They are utilized in various industries such as pharmaceutical, food industry and cosmetics. Even though they are capable to encapsulate both hydrophilic and lipophilic compounds, they can be modified using cholesterol, proteins and polymers to enhance their properties.

Presented work is focused on development and preparation of PHB-liposomes particles with different PHB content as well as PHB nanofibers. Characterization in terms of particle size, polydispersity index, colloidal stability and long-term stability were done. Sun protection factor was measured, too. Electron microscopy techniques (SEM, cryoTEM) were used to observe structure of prepared materials. To assess whether prepared particles are suitable for further application in cosmetics, MTT and LDH cytotoxicity assays on HaCaT cell line were carried out.

Our goal was to prepare and characterize PHB containing liposomes and nanofibers for potential application in cosmetic, pharmaceutical and food industry. Prepared particles were stable and had proper properties to be used as vehicles. Cytotoxicity assays showed that all materials were nontoxic to HaCaT cell line and, therefore, they can be ceded for further cytotoxicity as well as genotoxicity testing and in future potentially applicable in cosmetic industry.
\end{abstract}

Keywords: PBH, liposomes, nanofibers, cyto-toxicity, cosmetics

\section{INTRODUCTION}

Liposomes are versatile vehicles that are used for encapsulation and drug delivery in pharmaceutical industry as well as in cosmetics. They were firstly observed by Alec Bangham et al in 1960s [1]. Liposomes comprises of particles made of one or more phospholipid bilayer from biodegradable and biocompatible materials and aqueous environment entrapped in the middle part of the vesicle. Besides phospho- and sphingolipids their compositions could be altered by different compounds such as cholesterol, lipids and others [2]. Polyhydroxy alcanoates like poly-3-hydroxy butyrate are polyesters accumulated by numerous prokaryotes in the form of intracellular granules. The primary function of PHAs is the storage of carbon and energy. Recent research has shown that the biological function of PHAs is much more complex and that the capability to accumulate PHA has many biochemical and biophysical consequences. Their UV-protective action might be explained by their efficient UV-radiation scattering properties with high scattering efficiency in the wavelengths close to the DNA absorption maxima [3].

Our goal was to prepare and characterize liposomal particles enriched with poly-3-hydroxy butyrate and its nanofibers. As a new nanomaterial, both particles and fibers need to be evaluated by cytotoxicity assays like MTT and LDH. All these characterizations are important steps for final decision whether prepared materials are suitable for further application in cosmetics and other industries. 


\section{MATERIALS AND METHODS}

\subsection{Preparation of PHA/Liposomes}

Liposomal particles from phosphatidylcholine (PC, Sigma) and cholesterol (Serva) with different content of PHB (Hydal, Nafigate Co.) were prepared using sonication technique. Briefly, all compounds were dissolved in chloroform and add to water. Resulting mixture was sonicated for 1 min using 13-mm-diameter $20 \mathrm{kHz}$ ultrasound probe (Sonopuls, Bandelin). The organic solvent was evaporated. For further cytotoxicity testing, the particle suspension was centrifuged at $3600 \times \mathrm{g}$ for $5 \mathrm{~min}$. The supernatant was removed and centrifuged at $12200 \times \mathrm{g}$ for $1 \mathrm{~h}$. Finally, the liposomal pellet was resuspended in double amount of sterile distilled water and filtered through $0.22 \mu \mathrm{m}$ syringe filter to obtain uniform particle size.

\section{2. preparation of nanofibers}

Nanofibers were prepared using electrospinning technique, where PHB was dissolved in chloroform and $0.5 \%$ TEAB was add to enhanced conductivity. Parameters for electrospinning were $15 \mathrm{kV}, 15 \mathrm{~cm}$ distance between needle and collector, relative humidity $60 \%$, temperature $20^{\circ} \mathrm{C}$.

\subsection{Particle size and coloidal stability analysis}

Evaluation of particle size, polydispersity index $(\mathrm{Pdl})$ and colloidal stability in solution was done by standard procedure with Malvern Zetasizer Nano ZS. All samples of prepared particles were diluted 100times and $1 \mathrm{ml}$ od solution was plated into the cuvette. Colloidal stability was measured with same solution but with Dipp Cell.

\subsection{Long term stability}

Particle size, polydispersity index and colloidal stability were measured for 3 months to determine long-term stability.

\subsection{SPF measurment}

Prepared extracts were diluted with UV-VIS ethanol to concentration of $200 \mu \mathrm{g} \cdot \mathrm{ml}^{-1}$ and absorption spectra were measured at wavelengths $290-320 \mathrm{~nm}$. UV-VIS ethanol was used as blank. Calculation of SPF was done according to following Mansur equation (1).

$$
S P F=C F \cdot \sum_{290}^{320} E E(\lambda) \cdot I(\lambda) \cdot A b s(\lambda)
$$

Where CF is correlation factor (10), EE $(\lambda)$ is erythemogenic_effect at certain wavelength and Abs $(\lambda)$ is absorption of sample according to wavelength. Values of EE'I are constants defined by Sayre et. Al. (1979) and are given in Table 1.

Table 1 Values of constants to calculate SPF by Mansur equation

\begin{tabular}{|l|l|l|l|l|l|l|l|}
\hline$\lambda[\mathrm{nm}]$ & 290 & 295 & 300 & 305 & 310 & 315 & 320 \\
\hline EE $\cdot I$ & 0.0150 & 0.0817 & 0.2874 & 0.3278 & 0.1864 & 0.0837 & 0.0180 \\
\hline
\end{tabular}

\subsection{Imaging of nanomaterials}

Prepared particles were imaged by cryogenic transmission electron microscopy (cryo-TEM). Images were recorded at $200 \mathrm{kV}$ on FEI Tecnai F20 transmission electron microscope with 4 k CCD camera FEI Eagle. For cryo-sample preparation, $4 \mu$ l was deposited onto Quantifoil R2/1, mesh 200, and copper holey carbon grids. 
Vitrification in liquid ethane cooled by liquid nitrogen was conducted using a Vitrobot ${ }^{\mathrm{TM}}$ plunge freezing device (FEI) with a blot time of $2.0 \mathrm{~s}$, blot force -2 and $10.0 \mathrm{~s}$ wait time. Samples on grids were stored in liquid nitrogen until transferred to the cryo-holder Gatan 626 that provides cryo-conditions during imaging. Data were collected using automatic software packages EPU and Tomo. Surface structure and diameter of PHB nanofibers was analysed with JEOL JSM-7600F (SEM) electron microscope.

\subsection{Keratinocytes cultivation}

Cultivation of HaCaT keratinocytes was done in DMEM with High Glucose, with 0,4 mM L-Glutamine, without Sodium Pyruvate, with $10 \%$ FBS and $1 \%$ ATB in Cell cultivation box with atmosphere of $5 \% \mathrm{CO}_{2}$ at $37{ }^{\circ} \mathrm{C}$, fed every 2-3 days and passaged after reaching $80 \%$ of confluence.

\subsection{Cytotoxicity assay}

MTT assay [4], [5] was used to assess the cytotoxicity of prepared nanoparticles. Tested particles were treated as follows. Particles were diluted 1:1 with deionized water, pipetted through $200 \mathrm{~nm}$ syringe filter and diluted with DMEM till concentration range of 2-14\%. First, $100 \mu$ of cell culture was added into 96-well plate and for nanofiber testing cell culture was added to 6-well plate and let in the cultivator After $24 \mathrm{~h}$ medium was replaced by prepared samples in DMEM and placed back to the cultivator. Control sample was the medium alone, and ethanol served as negative control. Subsequently after another $24 \mathrm{~h} 20 \mu \mathrm{l}$ of MTT dissolved in PHB $(2,5 \mathrm{mg}$ $\mathrm{ml}^{-1}$ ) was added to each sample and incubated for $3 \mathrm{~h}$ in cultivator and then $100 \mu \mathrm{l}$ of $10 \%$ SDS in PBS was added to each well. Plates were stored in darkness and evaluated next day by ELISA Reader at $543 \mathrm{~nm}$.

\subsection{LDH Assay}

LDH is a stable enzyme occurring in cytosol. When cells undergo some reaction that lead to the damage of plasma membrane, LDH is rapidly released to cell culture media and therefore can be determined 6]. LDH assay was performed according to Brown et al [7] with modifications. For this assay supernatants form exposure were used. If they were not used for the assay immediately, they were kept frozen at $-80^{\circ} \mathrm{C}$. A calibration curve was prepared using sodium pyruvate/NADH solution. This solution consists of $1 \mathrm{mg} \cdot \mathrm{ml}^{-1}$ $\mathrm{NADH}$ in $0.75 \mathrm{mM}$ sodium pyruvate that were equivalent for LDH activity 0-2 $000 \mathrm{U} \mathrm{ml}^{-1}$. For determination of LDH activity $10 \mu \mathrm{l}$ of exposed supernatant, blank and $60 \mu \mathrm{l}$ calibration solution was pipetted in 96-well plate in triplicates. For samples and blank $50 \mu \mathrm{l}$ of pyruvate/NADH solution was added and incubated at $37{ }^{\circ} \mathrm{C}$ for $30 \mathrm{~min}$. After incubation $50 \mu \mathrm{l}$ of $4 \mathrm{M}$ sodium hydroxide was added to all wells and incubated at room temperature for $5 \mathrm{~min}$ in dark. Last step was measuring the absorbance at $540 \mathrm{~nm}$. Data are measured in absolute LDH activity units.

\section{RESULTS AND DISCUSSION}

In this study, nanomaterials comprising liposomal particles enriched with PHB and nanofibers from PHB tailored by electrospinning technique were prepared and characterized to see whether they are suitable for further application in cosmetic industry. Characterization of prepared particles were done in terms of particle size, polydispersity index, $\zeta$ - potential, Sun Protection Factor (SPF), amount of phospholipids, cytotoxicity and cryo-TEM imaging. Nanofibers were characterized by SEM imaging and cytotoxicity testing.

\subsection{Particle characterization}

Prepared particles were characterized using Zeta sizer Nano ZS. Results are displayed in Table 2. 
Table 2 Particle size (d), polydispersity index (Pdl) and colloidal stability ( $\zeta$-potential)

\begin{tabular}{|c|c|c|c|c|}
\hline sample & $\mathbf{d}(\mathbf{n m})$ & Pdl (-) & $\zeta$-potencial (mV) & SPF (-) \\
\hline liposomes & $148.7 \pm 0.4$ & $0.167 \pm 0.007$ & $-31.3 \pm 2.14$ & $1.70 \pm 0.06$ \\
\hline $10 \%$ PHB & $257.2 \pm 3.2$ & $0.388 \pm 0.023$ & $-40.8 \pm 1.2$ & $2.98 \pm 0.05$ \\
\hline $50 \%$ PHB & $535.9 \pm 28.2$ & $0.567 \pm 0.058$ & $-42.0 \pm 2.1$ & $15.18 \pm 0.30$ \\
\hline $100 \%$ PHB & $308.9 \pm 30.6$ & $0.404 \pm 0.100$ & $-25.4 \pm 1.5$ & $12.74 \pm 0.08$ \\
\hline
\end{tabular}

From results displayed in Table 2 we can see that all particles have diameter under $600 \mathrm{~nm}$ and their polydispersity is for most cases under 0.4 , so, they are monodispersed. Concerning their colloidal stability, we can say they are stable, because their zeta-potential is lower than $-25 \mathrm{mV}$. The same could be told for particles with zeta-potential higher than $+25 \mathrm{mV}$. SPF measuring confirms that with increasing amount of PHB the values of SPF increases as well.

Table 3 Long term stability of prepared particles after 4 months

\begin{tabular}{|c|c|c|c|}
\hline sample & $\mathbf{d}(\mathbf{n m})$ & Pdl $(-)$ & $\zeta$ - potencial $(\mathbf{m V})$ \\
\hline liposomes & $132.7 \pm 0.76$ & $0.177 \pm 0.01$ & $-24.2 \pm 2.67$ \\
\hline $10 \%$ PHB & $265.8 \pm 3.15$ & $0.376 \pm 0.06$ & $-35.9 \pm 0.95$ \\
\hline $50 \%$ PHB & $415.2 \pm 5.11$ & $0.437 \pm 0.02$ & $-32.6 \pm 5.27$ \\
\hline $100 \%$ PHB & $334.1 \pm 38.1$ & $0.398 \pm 0.02$ & $-24.2 \pm 0.66$ \\
\hline
\end{tabular}

After comparison of data from Tables 2 and $\mathbf{3}$ we can conclude that all prepared particles are stable for 4 months and, therefore, suitable for further application.

\subsection{Imaging of prepared nanomaterials}

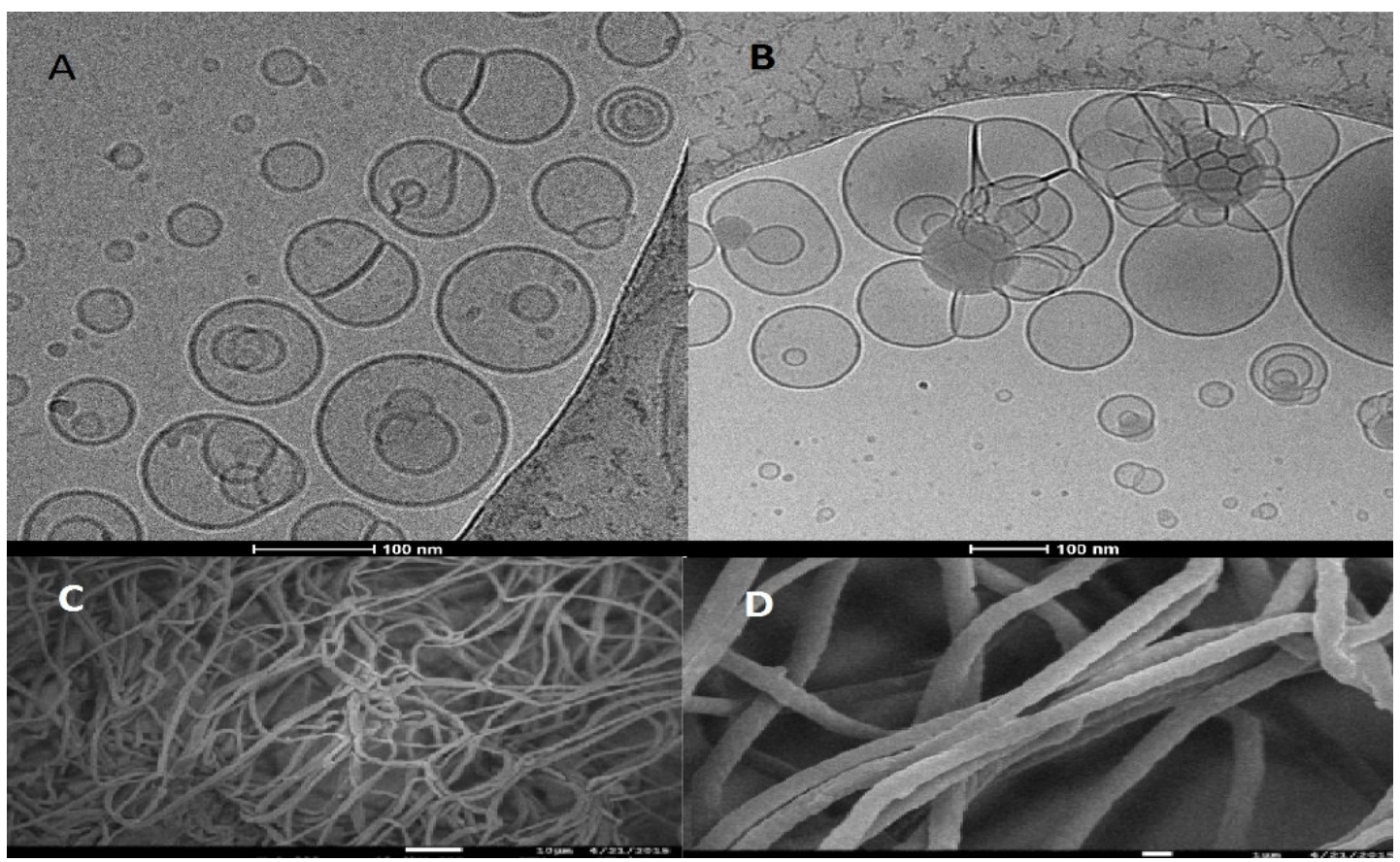

Figure 1 Cry-TEM imaging of A-liposome particles, B-liposome particles with $10 \%$ of PHB, $\mathrm{C}$ and $\mathrm{D}$ - PHB nanofibers prepared by electrospinning technique 


\subsection{Cytotoxicity testing}

With all prepared materials cytotoxicity testing was done with MTT and LDH assays. On Figure 2 we can see results from MTT testing on HaCaT cell line for liposomal particles. Liposomes as well as liposomes enriched with $10 \%$ and $50 \%$ of PHB had no cytotoxic effect on cell at all tested concentrations. Particles with $100 \%$ of PHB were not cytotoxic at least at 4 different concentrations in the range of $0-8 \%$. For PHB nanofibers the cell viability was $92.4 \% \pm 4.2 \%$ so we can say that this material is not cytotoxic to HaCaT cell line.

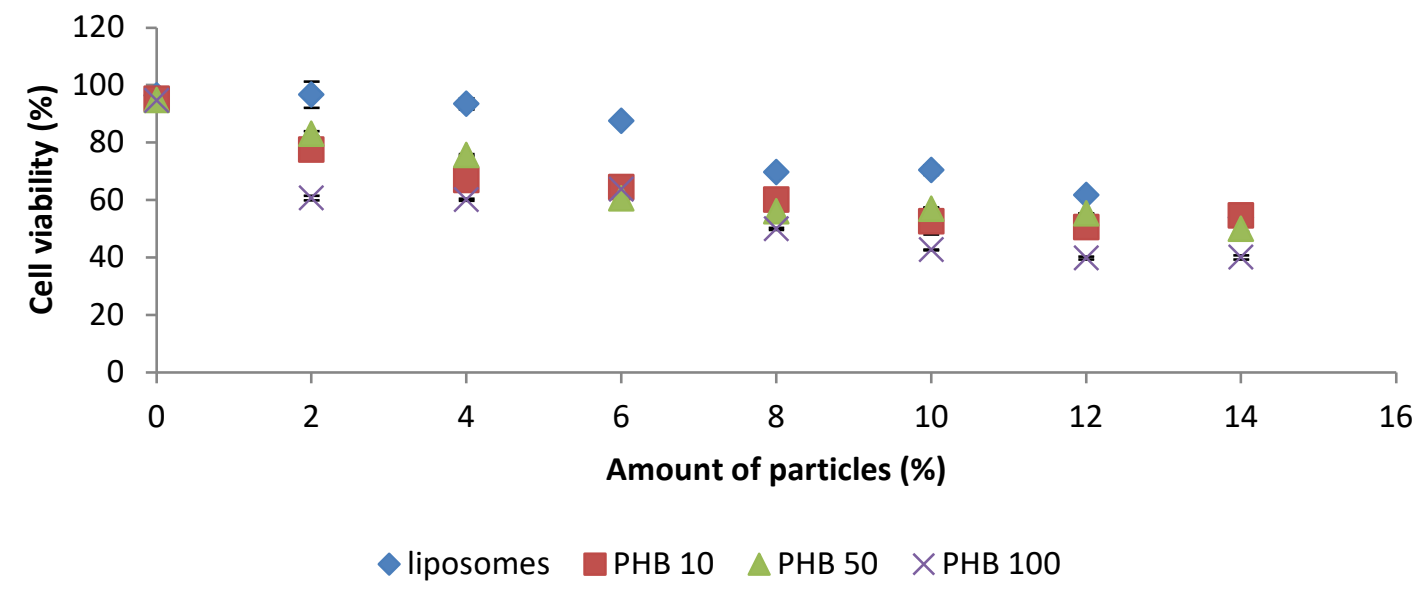

Figure 2 MTT assay of prepared particles

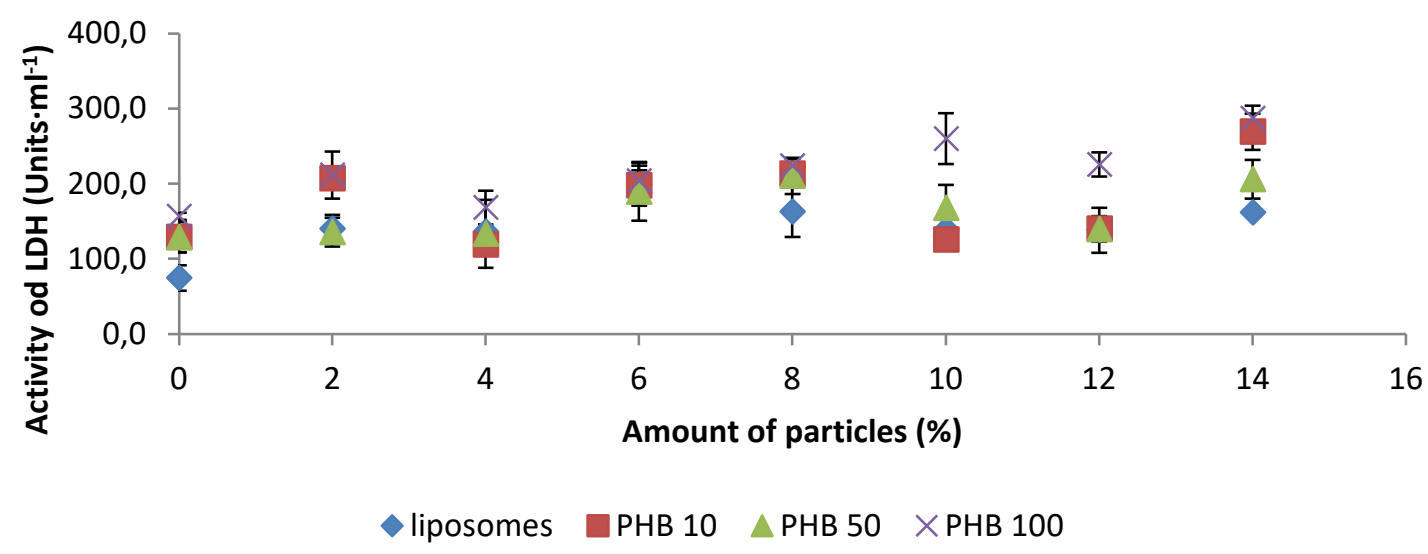

Figure 3 LDH assay of prepared particles

From the data demonstrated in the Figure 3 we can see that activity of LDH of prepared samples was very similar to cell control. So, no cytotoxic effect was observed on HaCaT cells. The same results came from PHB nanofibers, where the LDH activity was $241.2 \pm 16.9 \mathrm{U} \cdot \mathrm{ml}^{-1}$ and no cytotoxic activity observed as well.

\section{CONCLUSION}

We prepared liposome particles enriched with biocompatible polymer PHB. Amount of added PHB altered liposomal size, polydispersity, colloidal stability, and SPF. Cryo-transmission electron microscopy verified that higher concentration of polymer resulted in an increase of particle size. Particles were stable for the period of 3-months with no dramatic change in particle size, polydispersity and zeta-potential. Electro-spun PHB-based nanofibers had diameters ranging $500-800 \mathrm{~nm}$. 
MTT and LDH Cytotoxicity assays on HaCaT cell line showed that all types of particles at all tested concentrations as well as nanofibers were non-cytotoxic. Both liposomes and liposomes enriched with PHB are stable with desired properties and if further cytotoxicity and genotoxicity testing will show the same results, they will be suitable for further application in cosmetics.

\section{ACKNOWLEDGEMENTS}

This research was supported by the project FCH-S-19-5983 of the Research Foundation ofBrno University of Technology.

The authors received financial support of the measurements at the CF Cryo-electron Microscopy and Tomography from the CIISB research infrastructure project LM2015043 funded by MEYS CR.

\section{REFERENCES}

[1] BAREL, André O., Marc PAYE and Howard I. MAIBACH. Handbook of cosmetic science and technology. 2rd ed. New York: Informa Healthcare, 2009. p. 662.

[2] SHARMA, Amarnath and Uma S. SHARMA. Liposomes in drug delivery: Progress and limitations. International Journal of Pharmaceutics [online], 1997. vol. 154, iss. 2, pp.123-140 [viewed 2018-05-21]. Available from: https://doi.org/10.1016/s0378-5173(97)00135-x.

[3] SLANINOVA, Eva, Petr SEDLACEK, Filip MRAVEC, Lucie MULLEROVA, Ota SAMEK, Martin KOLLER, Ondrej HESKO, Dan KUCERA, Ivana MAROVA and Stanislav OBRUCA. Light scattering on PHA granules protects bacterial cells against the harmful effects of UV radiation. Applied Microbiology and Biotechnology [online]. 2018. vol. 102, iss. 4, pp. 1923-1931 140 [viewed 2019-10-01]. Available from: https://doi.org/10.1007/s00253-0188760-8.

[4] MOSMANN, Tim. Rapid colorimetric assay for cellular growth and survival: application to proliferation and cytotoxicity assays. Journal of Immunological Methods. 1983. vol 65, pp.55-63

[5] LI, Xueshu, Jaroslav TURÁNEK, Pavlína KNÖTIGOVÁ, Hana KUDLÁČKOVÁ, Josef MAŠEK, Sean PARKIN, Stephen E. RANKIN, Barbara L. KNUTSON and Hans-Joachim LEHMLER. Hydrophobic Tail Length, Degree of Fluorination And Headgroup Stereochemistry Are Determinants Of The Biocompatibility Of (Fluorinated) Carbohydrate Surfactants. Colloids and Surfaces B: Biointerfaces [online]. 2009. vol. 73, iss. 1, pp 65-74. [viewed 2019-11-28]. Available from: https://doi.org/10.1016/j.colsurfb.2009.04.023.

[6] BOKROVA, Jitka, Ivana MAROVA, Petra MATOUSKOVA and Renata PAVELKOVA. Fabrication of novel PHBliposome nanoparticles and study of their toxicity in vitro. Journal of Nanoparticle Research [online]. 2019. vol. 21, iss. 3, pp. 1-12 [viewed 2019-10-01]. Available from: https://doi.org/10.1007/s11051-019-4484-7.

[7] BROWN, David M., Martin R. WILSON, William A. MACNEE, Vicki STONE and Ken DONALDSON. SizeDependent Proinflammatory Effects of Ultrafine Polystyrene Particles: A Role for Surface Area and Oxidative Stress in the Enhanced Activity of Ultrafines. Toxicology and Applied Pharmacology [online]. 2001. vol. 175, iss. 3, pp. 191-199 [viewed 2020-01-06]. Available from: https://doi.org/10.1006/taap.2001.9240. 